\title{
Aplikasi Metode Geolistrik untuk Mengetahui Sebaran Batubara di Kabupaten Tulungagung Jawa Timur
}

\author{
Rusli*, Elvira Azizah, dan Abdul Basid \\ Jurusan Fisika, FST UIN Maulana Malik Ibrahim Malang, Indonesia \\ * email: rusli@fis.uin-malang.ac.id
}

Received: September 21st 2019 . Accepted: Desember 29th 2019. Published: February $29^{\text {th }}, 2020$

\begin{abstract}
Abstrak
Telah dilakukan penelitian yang bertujuan untuk mengetahui sebaran batubara di bawah permukaan di Kabupaten Tulungagung. Survei yang dilakukan dalam penelitian ini menggunakan survey geolistrik resistivitas konfigurasi wenner. Pengambilan data geolistrik resistivitas di lapangan sebanyak empat lintasan. Hasil pengambilan data di lapangan pada tiap lintasan diolah dengan menggunakan pemodelan $2 \mathrm{D}$ pada software Res2dinv. Hasil pengolahan pemodelan dua dimensi kemudian diinterpretasi. Struktur lapisan batuan yang mengandung batubara ditunjukkan oleh skema warna kuning, merah, hingga ungu tua dengan nilai resistivitas 75-350 ohm meter dengan kedalaman yang bervariasi mulai dari 0 meter sampai 6,91 meter di bawah permukaan menyebar tak menentu dan terpetak-petak pada tiap lintasan.
\end{abstract}

\begin{abstract}
Research has been conducted aiming to determine the distribution of coal below the surface in Tulungagung Regency. The survey conducted in this study used a Wenner configuration resistivity geoelectric survey. Retrieval of geolithic resistivity data in the field of four trajectories. The results of data collection in the field oneach track are processed using 2D modeling in Res2dinv software. The results of the processing of the two-dimensional modeling are then interpreted. The structure of rock layers containing coal is shown by a yellow, red to dark purple scheme with a resistivity value of 75-350 ohm meters on the inside varying from 0 meters to 6.91 meters below the surface, spreading erratically and patching on each track. (C2020PERJ
\end{abstract}

Keywords: Coal; geoelectric; Tulungagung. 


\section{PENDAHULUAN}

Kebutuhan energi semakin hari semakin meningkat. Selama ini energi yang banyak dipakai dalam memenuhi kehidupan manusia sehari-hari untuk beraktivitas baik langsung maupun tidak langsung adalah energi dari minyak dan gas bumi. Ketersediaan energi dari minyak dan gas bumi semakin hari semakin menipis karena di eksploitasi terus menerus dan besarbesaran (Santoso, dkk, 2016). Harga Bahan Bakar Minyak (BBM) khususnya di Indonesia yang mengalami kenaikan tidak menentu memicu banyak pihak untuk mencari sumber energi selain dari minyak dan gas bumi, salah satunya adalah energi yang berasal dari batubara.

Industri batubara di Indonesia kini semakin meningkat. Hal ini terlihat dari produksi batubara yang meningkat dari tahun ke tahun. Penggunaan batubara pada industri tekstil guna pemenuhan kebutuhan daya (power generation) naik secara signifikan dari 15\% pada tahun 2006 menjadi 19\% di tahun 2009 (Umar dan Nawir, 2017).

Batubara merupakan sumber daya alam yang tersusun dari bahan organik dan anorganik (Fitriani, dkk, 2013). Batubara adalah batuan sedimen yang terbentuk dari sisasisa tanaman purba. Sisa tanaman tersebut kemudian mengalami pengendapan dan proses kimia dan fisika sehingga terjadi pengayaan pada kandungan atom karbonnya (Sukandarrumidi, 2006). Batubara menghasilkan kalori yang cukup tinggi, yaitu antara 5.000 sampai 9.000 kalori setiap gram. Hal tersebut menjadikan batu bara sebagai bahan pembangkit tenaga listrik dan juga digunakan sebagai tenaga bahan industri skala besar maupun kecil (Azhar, 2001).

Keberadaan batubara di Tulungagung merupakan sebuah potensi dan kemungkinan menjadi jawaban untuk keberadaan pembangkit tenaga listrik uap yang berada di Kabupaten Trenggalek. Secara geologi, daerah yang digunakan dalam penelitian ini merupakan bagian dari formasi pegunungan selatan Jawa Timur yang morfologinya berbukit (Nahrowi, dkk, 1987). Hal ini memungkinkan terdapat batu bara di bawah permukaan daerah tersebut. Oleh sebab itu, perlu dilakukan survey untuk memetakan batubara yang berada di bawah permukan.

Salah satu survey untuk memetakan sebaran dan kedalaman batubara di bawah permukaan adalah survey geofisika metode geolistrik resistivitas. Geolistrik adalah salah satu metode dalam geofisika yang mempelajari sifat aliran listrik di dalam bumi (Yulianto dan Widodo, 2008). Melalui metode ini, dapat diperoleh hasil pengukuran potensial listrik dan arus listrik yang mengalir akibat adanya injeksi arus dalam tanah (Zubaidah dan Kanata, 2008). Metode geolistrik resistivitas pada prinsipnya mempelajari aliran 
listrik dan bagaimana cara mendeteksi serta mengukur besaran listrik tersebut dari atas permukaan bumi. Metode geolistrik juga dapat memberikan informasi mengenai beda parameter fisis daya hantar listrik antar batuan bawah permukaan (Umar dan Nawir, 2017). Diasumsikan dalam pengukuran geolistrik resistivitas dengan cara menginjekkan arus listrik ke bawah permukaan, medium di bawah permukaan tersebut homogen isotropis sehingga arus listrik merambat dan menyebar ke seluruh medium dengan nilai yang sama besar. Apabila arus listrik tersebut bertemu dengan batuan atau lapisan tertentu maka akan terjadi penyimpangan dari kondisi ideal, penyimpangan inilah yang diamati. Setiap batuan memiliki nilai resistivitas terntentu sehingga bisa dibedakan antara batuan yang satu dengan batuan yang lainnya (Telford, Gerdart, Sheriff, \& Keys, 1990).

Metode geolistrik resistivitas dapat dimanfaatkan untuk menentukan sebaran batubara, terlihat di antaranya dari penelitian Umar dan Nawir (2017). Beberapa pemanfaatan lain metode geolistrik resistivitas adalah untuk mendeteksi struktur tanah, seperti pada penelitian Wijaya, (2015) serta menentukan sebaran air tanah, misal pada penelitian Budiman, dkk (2013), Manrulu, dkk (2018), Sutasoma, dkk (2018) dan Faris, dkk (2019).

\section{Terdapat}

dua

metode pengukuran geolistrik di lapangan, yaitu metode sounding dan mapping (Loke \& Barker, 1996). Metode sounding bertujuan untuk mengetahui variasi resistivitas batuan perlapisan di bawah permukaan secara vertikal sedangkan metode mapping tidak hanya mendapatkan variasi resistivitas batuan perlapisan secara vertikal tapi juga lateral (Reynolds dan Jhon M, 2005). Metode yang digunakan pada penelitian ini adalah metode mapping sehingga didapatkan citra bawah permukaan baik secara vertikal maupun lateral.

\section{METODE}

Sebelum pengambilan data di lapangan, terlebih dahulu dilakukan studi literatur terhadap daerah penelitian. Langkah selanjutnya adalah melakukan survey langsung ke lapangan untuk menentukan tempat dimana saja untuk pengambilan data, yaitu menentukan lintasan pengambilan data geolistrik resistivitas. Setelah ditentukan lintasan pengambilan data, selanjutnya dilakukan pengambilan data geolistrik resistivitas dengan metode mapping.

Penelitian ini menggunakan seperangkat peralatan resistivity meter merk campus tigre (Swedia), GS, HT, rol meter, kompas payung, peta geologi dan peta topografi. Pengolahan datanya menggunakan seperangkat komputer dan software Res2Dinv yang dilakukan di lab 
geofisika Jurusan Fisika UIN Maulana Malik Ibrahim Malang.

Metode yang digunakan dalam pengambilan data di lapangan adalah dengan menggunakan metode geolistrik resistivitas konfigurasi wenner. Jumlah lintasan pengambilan data dalam penelitian ini sebanyak 4 lintasan. Lintasan pertama dengan panjang lintasan 105 meter, lintasan ke dua dengan panjang 70 meter, lintasan ke tiga 60 meter dan lintasan ke empat dengan panjang 65 meter. Terjadi perbedaan panjang lintasan tiap lintasan disebabkan medan topografi daerah penelitian yang tidak rata. Lintasanlintasan tersebut terletak di sekitar singkapan batu bara yang ada di lapangan. Setelah data diambil kemudian dilakukan pengolahan data dengan menggunakan software Res2Dinv untuk mendapatkan citra bawah permukaan 2D. Langkah terakhir dilakukan adalah interpretasi data yang diperoleh dari pengukuran.

\section{HASIL DAN PEMBAHASAN}

Lintasan pertama dengan panjang lintasan 105 meter terletak pada koordinat $08^{\circ} 16.141^{\prime} \mathrm{LS}$ dan $111^{\circ} 45.342^{\prime}$ BT sampai $08^{\circ} 16.186^{\prime}$ LS dan $111^{\circ} 45.336^{\prime}$ BT.

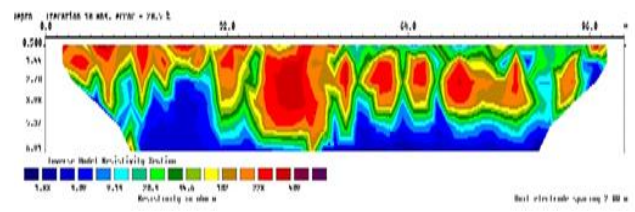

Gambar 1. Model Penampang 2D Lintasan 1
Gambar 1 menunjukkan terdapat pola dengan warna kuning, merah, sampai ungu dengan nilai resistivitas antara $75 \mathrm{ohm}$ meter sampai 600 ohm meter yang diinterpretasikan dengan lapisan batuan tersebut mengandung batubara. Lapisan batubara terdapat pada kedalaman 0 meter sampai 6,91 meter di bawah permukaan yang menyebar tidak menentu dan terpetak-petak. Warna biru sampai hijau muda dengan nilai resistivitas 2 ohm meter sampai 70 ohm meter dinterpretasikan dengan lapisan batuan lempung pasiran. Lempung pasiran ini berada di bawah lapisan batu bara.

Pada lintasan ke dua dengan panjang lintasan 70 meter terletak pada koordinat $08^{\circ} 16.157^{\prime} \mathrm{LS}$ dan $111^{\circ} 45.351^{\prime}$ BT sampai $08^{\circ} 16.190^{\prime}$ LS dan $111^{\circ} 45.344^{\prime}$ BT.

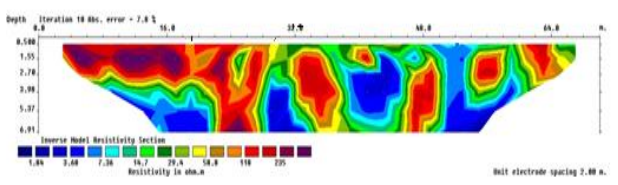

Gambar 2. Model Penampang 2D Lintasan 2

Gambar 2 memperlihatkan pola warna kuning, merah, sampai ungu dengan nilai resistivitas antara 60 ohm meter sampai $360 \mathrm{ohm}$ meter yang diinterpretasikan dengan lapisan batuan mengandung batubara. Lapisan batubara tersebut terdapat pada kedalaman dari 0 meter sampai 6,51 meter di bawah permukaan yang hampir sama dengan lintasan pertama, menyebar tidak menentu dan terpetak-petak. Warna biru sampai hijau muda 
dengan nilai resistivitas $2 \mathrm{ohm}$ meter sampai $55 \mathrm{ohm}$ meter dinterpretasikan dengan lapisan batuan lempung pasiran. Lempung pasiran ini berada di bawah dan diselah-selah lapisan batubara.

Lintasan ke tiga dengan panjang lintasan 60 meter terletak pada koordinat $08^{\circ} 16.160^{\prime}$ LS dan $111^{\circ} 45.361^{\prime}$ BT sampai $08^{\circ} 16.185^{\prime}$ LS dan $111^{\circ} 45.358^{\prime}$ BT.

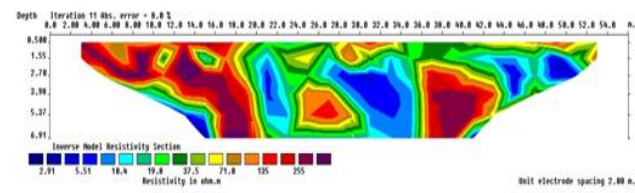

Gambar 3. Model Penampang 2D Lintasan 3

Gambar 3 memperlihatkan pola warna kuning, merah, sampai ungu dengan nilai resistivitas antara 75 ohm meter sampai $255 \mathrm{ohm}$ meter yang diinterpretasikan sebagai lapisan batuan mengandung batubara. Lapisan batubara tersebut terdapat pada kedalaman dari 0 meter sampai 6,42 meter di bawah permukaan, menyebar tidak menentu dan terpetak-petak terutama pada posisi sebelah kiri pada model penampang Gambar 3. Warna biru sampai hijau muda dengan nilai resistivitas $2 \mathrm{ohm}$ meter sampai 70 ohm meter dinterpretasikan dengan lapisan batuan lempung pasiran. Lempung pasiran ini berada di atas dan di sela-sela lapisan batubara.

Lintasan ke empat dengan panjang lintasan 65 meter, terletak pada koordinat $08^{\circ} 16.166^{\prime}$ LS dan $111^{\circ} 45.338^{\prime} \mathrm{BT}$ sampai $08^{\circ} 16.163^{\prime} \mathrm{LS}$ dan $111^{\circ} 45.365^{\prime} \mathrm{BT}$.

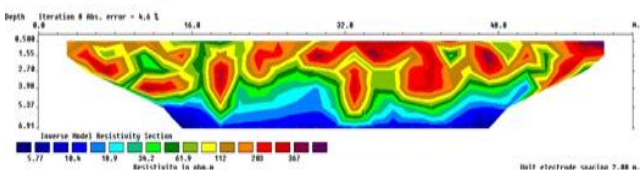

Gambar 4. Model penampang 2D lintasan keempat

Gambar 4 memperlihatkan pola warna kuning, merah, sampai ungu dengan nilai resistivitas antara 80 ohm meter sampai $380 \mathrm{ohm}$ meter yang diinterpretasikan sebagai lapisan batuan mengandung batu bara. Lapisan batubara tersebut terdapat pada kedalaman dari 0 meter sampai 5,42 meter di bawah permukaan terutama menyebar tidak menentu dan terpetak-petak secara merata pada lapisan atas. Warna biru sampai hijau muda dengan nilai resistivitas $6 \mathrm{ohm}$ meter sampai $70 \mathrm{ohm}$ meter dinterpretasikan dengan lapisan batuan lempung pasiran. Keberadaan lempung pasiran ini terdapat di bawah dan di sela-sela batubara.

Perpaduan lintasan pertama hingga ke empat dapat diilustrasikan seperti Gambar 5. Lintasan pertama, ke dua, dan ke tiga terlihat sejajar; sedangkan lintasan ke empat memotong lintasan pertama, ke dua dan ke tiga.

Secara umum, sebaran batubara menyebar di seluruh area penelitian dengan bentuk yang terpetak petak pada kedalaman 0 meter sampai 6,9 meter di bawah permukan. Antara sela-sela petak batubara tersebut diisi oleh lempung pasiran yang 
juga tersebar di seluruh area penelitian. Diharapkan penelitian selanjutnya dapat mengcover seluruh area penelitian. Kendala yang ditemui dalam penelitian ini adalah medan yang bergelombang dan bertebing serta terdapat sungai sehingga menyebabkan kesulitan dalam pengambilan data geolistrik.

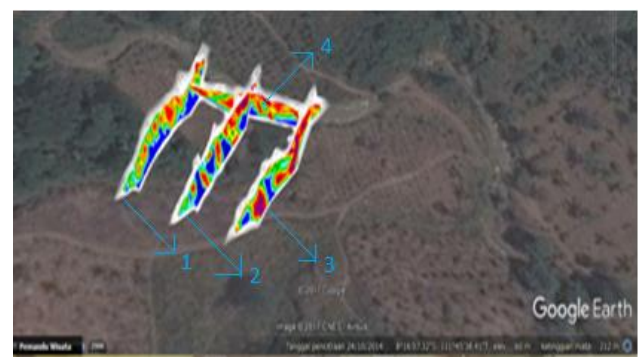

Gambar 5. Sebaran batu bara pada lintasan 1, 2, 3 dan 4

\section{KESIMPULAN}

Pada lintasan pertama, ke dua, ke tiga maupun ke empat; lapisan batubara diinterpretasikan dengan nilai resistivitas yang tinggi antara 75-350 ohm meter; sedangkan untuk nilai resistivitas yang rendah antara 3-70 ohm meter diinterpretasikan dengan lempung pasiran. Batubara di daerah penelitian tersebar secara merata dan terpetak-petak pada kedalaman 0 meter sampai 6,9 meter di bawah permukaan. Antara selasela batubara yang terpetak-petak terisi dengan batuan lempung pasiran yang juga tersebar di seluruh area penelitian.

\section{UCAPAN TERIMA KASIH}

Ucapan terimakasi kami sampaikan kepada Ketua Jurusan
Fisika UIN Maulana Malik Ibrahim Malang. Ke dua, ucapan terimakasih kepada ketua lab geofisika Jurusan Fisika UIN Maulana Malik Ibrahim Malang, serta kepada mahasiswa yang berkecimpung di dalam penelitian ini terutama yang ikut ke lapangan mengambil data geolitrik resistivitas.

\section{DAFTAR PUSTAKA}

Azhar. 2001. Pemodelan Fisis Metode Resistivity untuk Eksplorasi batubara. ITB.

Budiman, A., Delhasni dan Widjojo, S. A. H. S. 2013. Pendugaan Potensi Air Tanah dengan Metode Geolistrik Tahanan Jenis Konfigurasi Schlumberger. Jurnal Ilmu Fisika (JIF), 5 (2): 72-78.

Faris, A. N., Suaidi, D. A., Sutrisno, Hasan, M. F. R., dan Broto, A. B. 2019. Identifikasi Sebaran Akuifer dengan Metode Geolistrik Resistivitas Konfigurasi Schlumberger di Desa Gedangan, Kecamatan Gedangan, Kabupaten Malang. NATURAL B, 5 (1): 28-34.

Fitriani, I., Musa, M. D. T., dan Sandra. 2013. Identifikasi Sebaran Batubara Menggunakan Metode Geolistrik Hambatan Jenis Di Desa Lemban Tongoa. Gravitasi, 15 (1): 1-6.

Loke, M. H. dan Barker, R. D. 1996. Rapid Least Squares Inversion of Apparent Resistivity Pseudosection by a quasiNewton Method. Geophysical 
Prospecting, 131-152.

Manrulu, R. H., Nurfalaq, A., dan Hamid, I. D. 2018. Pendugaan Sebaran Air Tanah Menggunakan Metode Geolistrik Resistivitas Konfigurasi Wenner dan Schlumberger Di Kampus 2 Universitas Cokroaminoto Palopo. Jurnal Fisika FLUX, 15 (1): 6-12.

Nahrowi, T. Y., Namida, S. ., dan Hidayat, S. 1987. Geologi Pegunungan Selatan Jawa Timur. PIT IX Ikatan Ahli Geologi Indosesia. Bandung.

Reynolds dan Jhon M. 2005. An Introduction to Applied and Environmental Geophysics. USA: JhonWiley \& Sons.

Santoso, B., Wijatmoko, B., Supriyana, E., dan Harja, A. 2016. Penentuan resistivitas batubara menggunakan metode electrical resistivity tomography dan vertical electrical sounding. Jurnal Material Dan Energi Indonesia, 06 (01): 8-14.

Sukandarrumidi. 2006. Batubara dan Pemanfaatannya. Yogyakarta: Gadjah Mada University Press. Sutasoma, M., Azhari, A. P., dan Arisalwadi, M. 2018. Identifikasi Air Tanah dengan Metode Geolistrik Resistivitas Konfigurasi Schlumberger di
Candi Dasa Provinsi Bali. Jurnal Fisika Dan Pendidikan Fisika, 3 (2): 58-65.

Telford, M. W., Gerdart, L. P., Sheriff, R. E., dan Keys, D. 1990. Applied Geophysics. USA: Cambrige University Press.

Umar, E. P. dan Nawir, A. 2017. Analisis Resistivitas Batu Bara Barru Dusun Palluda Kabupaten Barru Provinsi Sulawesi Selatan. Jurnal Geomine, 5 (1): 48-52.

Wijaya, A. S. 2015. Aplikasi Metode Geolistrik Resistivitas Konfigurasi Wenner Untuk Menentukan Struktur Tanah di Halaman Belakang SCC ITS Surabaya. Jurnal Fisika Indonesia, 19 (55): 1-5.

Yulianto, T. dan Widodo, S. 2008. Identidikasi Penyebaran dan Ketebalan Batubara Menggunakan Metode Geolistrik Resistivitas (Studi Kasus Daerah X Kabupaten Kuati Kertanegara Kalimatan Timur). Berkala Fisika, 11 (2): 59-66.

Zubaidah, T. dan Kanata, B. 2008. Pemodelan Fisika Aplikasi Metode Geolistrik Konfigurasi Schlumberger untuk Investigasi Keberadaan Air Tanah. Pemodelan Fisika Aplikasi, 7 (1): 20-24. 
Phy. Educ. Res. J. Vol. 2 No. 1 (2020), 51-58 